\title{
Gestão de pessoas: estudo de caso do clima organizacional em uma instituição pública
}

People management: case study of the organizational climate in a public institution

Gestión de personas: estudio de caso del clima organizacional en una institución pública

Recebido: 09/05/2020 | Revisado: 11/05/2020 | Aceito: 12/05/2020 | Publicado: 21/05/2020

David Nogueira Silva Marzzoni

ORCID: http://orcid.org/0000-0002-0004-8739

Universidade Federal do Sul e Sudeste do Pará, Brasil

E-mail: davidmarzzoni@gmail.com

Yanna Patrícia Araújo Pereira

ORCID: http://orcid.org/0000-0002-7394-2811

Universidade Federal do Sul e Sudeste do Pará, Brasil

E-mail: yanna@unifesspa.edu.br

\section{Resumo}

Este trabalho analisou a influência dos fatores que afetam o clima organizacional dentro de uma organização pública. Buscou-se, como objetivo geral, diagnosticar a percepção e a satisfação dos servidores técnico-administrativos da Secretaria de Estado da Educação da Paraíba em relação ao ambiente de trabalho, sugerindo-se ações que auxiliem a organização na superação das suas fragilidades, consonante aos resultados obtidos. Do universo de 197 servidores, 120 participaram da pesquisa, representando $61 \%$ do quadro de pessoal administrativo do órgão investigado. A metodologia adotada foi: pesquisa bibliográfica e de campo, tendo-se utilizado um questionário de coleta de dados baseado no modelo de BurkeLitwin, integrado por doze dimensões que influenciam o desempenho da organização, relacionando-os ao seu modelo de gestão, cultura, estrutura e clima interno. A análise e interpretação dos dados se deram por abordagem quantitativa. No que concerne à revisão bibliográfica, abordou-se temáticas relacionadas a comportamento organizacional, gestão de pessoas, relacionamento interno, liderança, qualidade de vida no trabalho, motivação e clima organizacional. A partir dos resultados obtidos, concluiu-se que os respondentes estão medianamente satisfeitos com o seu ambiente de trabalho, ressaltando-se como elementos para uma ação corretiva imediata a desmotivação dos servidores, especialmente em relação ao 
salário, benefícios e reconhecimento, bem como a insatisfação com o relacionamento mantido com a alta gestão da organização.

Palavras-chave: Comportamento; Gestão de pessoas. Clima organizacional.

\begin{abstract}
This paper analyzed the influence of factors that affect the organizational climate within a public organization. The general objective was to diagnose the perception and satisfaction of the technical and administrative employees of the Paraíba State Department of Education in relation to the work environment, suggesting actions that help the organization to overcome its weaknesses, in line with the results obtained. Of the universe of 197 civil servants, 120 participated in the survey, representing $61 \%$ of the administrative staff of the investigated body. The methodology adopted was bibliographic and field research, using a data collection questionnaire based on the Burke-Litwin model, integrated by twelve dimensions that influence the performance of the organization, relating them to its management model, culture , structure and internal climate. The analysis and interpretation of the data took place using a quantitative approach. With regard to the literature review, topics related to organizational behavior, people management, internal relationships, leadership, quality of life at work, motivation and organizational climate were addressed. From the results obtained, it was concluded that the respondents are moderately satisfied with their work environment, standing out as elements for an immediate corrective action the demotivation of the employees, especially in relation to salary, benefits and recognition, as well as the dissatisfaction with the relationship maintained with the top management of the organization.
\end{abstract}

Keywords: Behavior; People management; Organizational climate.

\title{
Resumen
}

Este artículo analizó la influencia de factores que afectan el clima organizacional dentro de una organización pública. El objetivo general fue diagnosticar la percepción y satisfacción de los empleados técnicos y administrativos del Departamento de Educación del Estado de Paraíba en relación con el entorno laboral, sugiriendo acciones que ayuden a la organización a superar sus debilidades, en línea con el resultados obtenidos. Del universo de 197 funcionarios, 120 participaron en la encuesta, lo que representa el $61 \%$ del personal administrativo del organismo investigado. La metodología adoptada fue la investigación bibliográfica y de campo, utilizando un cuestionario de recolección de datos basado en el modelo de Burke-Litwin, integrado por doce dimensiones que influyen en el desempeño de la 
organización, relacionándolas con su modelo de gestión, cultura, estructura y clima interno. El análisis e interpretación de los datos se realizó utilizando un enfoque cuantitativo. Con respecto a la revisión de la literatura, se abordaron temas relacionados con el comportamiento organizacional, gestión de personas, relaciones internas, liderazgo, calidad de vida en el trabajo, motivación y clima organizacional. A partir de los resultados obtenidos, se concluyó que los encuestados están moderadamente satisfechos con su entorno de trabajo, destacando como elementos para una acción correctiva inmediata la desmotivación de los empleados, especialmente en relación con el salario, los beneficios y el reconocimiento, así como el insatisfacción con la relación mantenida con la alta dirección de la organización.

Palabras clave: Comportamiento; Gestión de personas; Clima organizacional.

\section{Introdução}

Segundo Ribeiro (2005) a administração com pessoas significa alinhar os objetivos intrínsecos dos colaboradores aos objetivos organizacionais, permitindo o surgimento da parceria entre empresa e sujeito ativo empreendedor de suas ações, e não somente agente passivo no processo de mudança dos desafios futuros. Urge que as organizações se preparem para desenvolver, em conjunto com os colaboradores, melhores práticas organizacionais e com essas experiências forjarem um desempenho padrão que leve à excelência na sua área de atuação.

Marzzoni et al. (2020) considera o grau de escolaridade importante para o melhor gerenciamento da organização, pois um maior conhecimento acerca de determinados instrumentos pode auxiliar na tomada de decisões. No âmbito do setor público, servidores com maior formação facilita o gerenciamento de pessoas. Bergue (2007, p. 18) afirma que gestão de pessoas é o “[...] esforço orientado para o suprimento, a manutenção e o desenvolvimento de pessoas nas organizações públicas, em conformidade com os ditames constitucionais e legais, observadas as necessidades e condições do ambiente em que se inserem”. No setor público, a gestão de pessoas ainda possui um desafio maior, devido à necessidade de seguir o que rege a legislação da área, além de fazer a prestação de contas ao cenário público, por se tratar de um serviço subsidiado por todos os cidadãos da sociedade. Muito embora, não seja difícil buscar a excelência e boas práticas de gestão de pessoas voltadas para um melhor desempenho dos servidores, que são o maior patrimônio de qualquer instituição.

A partir deste entendimento, os estudos do comportamento organizacional sondam 
continuamente o indivíduo dentro da organização, para conquistar um espaço favorável ao sucesso de ambos os atores organizacionais. Para Robbins (2005, p. 6): O comportamento organizacional é um campo de estudos que investiga o impacto que indivíduos, grupos, e a estrutura têm sobre o comportamento dentro das organizações, com o propósito de utilizar esse conhecimento para promover a melhoria da eficácia organizacional.

Promover a constante participação dos colaboradores em qualquer organização torna os funcionários comprometidos com o bom desempenho nela. De acordo Marzzoni et al. (2020) precisa "abrir" espaço para um novo, ou seja, da mais liberdade para o profissional que tenha como características ser mais arrojado, estratégico, flexível e minucioso. Para assim se sentir mais seguro para trabalhar.

As pesquisas de clima organizacional são fundamentais no intuito de analisar diversas variáveis que sustentam a percepção dos colaboradores acerca da liderança, motivação, condições de trabalho, etc., no seu ambiente laboral.

Tendo em vista que o clima organizacional influi diretamente na motivação da equipe, no seu grau de satisfação e, consequentemente, na qualidade de seu trabalho, é bastante importante para as empresas mensurarem a percepção que os colaboradores têm delas.

Chiavenato (2008) corrobora com este entendimento quando afirma que as pesquisas de clima são excelentes instrumentos para avaliar a função de gestão de pessoas, pois compilam informações do campo psicológico e do ambiente de trabalho, identificando a sensação das pessoas nesse cenário - como interage uma com as outras, com clientes e fornecedores, evidenciando informações relevantes sobre quais os principais fatores que podem ser melhorados, tornando-se relevante que se realizem estudos nesse sentido.

Marzzoni et al (2020) no que tange à pesquisa de satisfação dos colaboradores no serviço privado, às pesquisas no setor público são semelhantes, é preciso que haja um plano transparente e que demostre todas as habilidades e atitudes que os profissionais das empresas necessitam para trabalhar e gerar melhores resultados.

Nos processos de melhoria do desempenho de qualquer instituição, é preciso haver investimentos em estudos de percepção dos agentes envolvidos nas atividades desenvolvidas, intencionando descobrir suas necessidades dentro da organização. Foi a observação da falta de ferramentas que fez com que buscássemos desenvolver este trabalho, com a proposta de demonstrar a eficácia do tipo de projeto no que tange à participação dos colaboradores da organização.

Esta pesquisa auxilia a Secretaria de Estado da Educação no conhecimento do clima interno da instituição e de quais são as solicitações de melhoria do público estudado. Neste 
caso específico, foram selecionados os servidores efetivos recém-admitidos, no concurso público do ano de 2013. Por serem novos no serviço da instituição, eles puderam opinar sem os vícios de um veterano acerca do clima organizacional, sendo avaliados os critérios que dizem respeito à participação nos processos de decisão, às práticas de gestão utilizadas e todos os outros fatores que constituem os processos de uma típica instituição pública.

Portanto, foi avaliado como problema de pesquisa a seguinte indagação: qual o nível de satisfação dos colaboradores da organização pesquisada em relação aos principais fatores que determinam o clima organizacional?

Diante disso o trabalho teve como objetivo diagnosticar a percepção e a satisfação dos servidores da Secretaria de Estado da Educação da Paraíba em relação ao ambiente de trabalho, por meio de uma pesquisa de clima organizacional.

Assim esta pesquisa teve como ponto de partida o interesse da autora por gestão de pessoas e satisfação no trabalho, no contexto da Secretaria de Estado da Educação da Paraíba, por pertencer ao quadro de servidores, atuando na Gerência de Recursos Humanos. As demandas do contexto profissional levaram à feitura de uma Pós-graduação na área de Gestão Pública, consolidando a partir das abordagens teórico-práticas, a decisão em desenvolver uma pesquisa de clima organizacional na instituição, pelas contribuições que poderiam trazer à qualidade de vida no ambiente de trabalho.

Com a publicitação dos resultados desta pesquisa junto ao Secretário da Pasta e ao setor de Recursos Humanos, esperamos contribuir para a minimização/superação dos problemas encontrados. Além do que, acreditamos que este estudo aumentará o conhecimento organizacional acerca de quais políticas e práticas de gestão de pessoas melhorar ou implementar, ampliando o posicionamento estratégico da área de Recursos Humanos. Pretendemos, com esta pesquisa, divulgar os resultados aos Secretários da Pasta e ainda ao setor de RH, objetivando contribuir para a minimização/superação dos problemas encontrados.

Oportunamente, a abordagem poderá gerar outras pesquisas nessa perspectiva ou mesmo mais aprofundadas, com o intuito de melhorar continuamente a gestão da instituição. Para alcançarmos uma Gestão Pública eficiente, precisamos de colaboradores envolvidos e participantes dos resultados, mas é preciso compreender que as pessoas só se sentem partes do processo quando são conclamadas a opinar e sugerir. Diagnosticar o clima organizacional é o começo da gestão participativa.

Esses diagnósticos e pesquisas organizacionais envolvem o servidor com a empresa e com suas ações, passam maior credibilidade às relações trabalhistas e ainda criam um círculo 
virtuoso de feedback das ações desenvolvidas. Portanto, este trabalho poderá abrir portas para melhorias consideráveis no que tange aos fatores que serão analisados, gerando maior eficiência, eficácia e efetividade das ações da Secretaria. Além disso, poderá proporcionar maior satisfação dos funcionários, que se sentirão valorizados e engajados nos processos, ao serem questionados a respeito do que está sendo desenvolvido na instituição.

\section{Procedimentos Metodológicos}

Para o desenvolvimento dos procedimentos metodológicos, optamos pela pesquisa de campo. Esta pesquisa pode ser classificada como descritiva, na medida em que observamos, analisamos e registramos as circunstâncias exatamente como são, no contexto do órgão investigado, no sentido de descrever determinado fenômeno, a partir de descrições quantitativas (Marconi \& Lakatos, 2006; Gil, 2010; Pereira et al., 2018).

Quanto à forma de abordagem, as opiniões coletadas junto aos respondentes, a partir da aplicação de questionário estruturado, receberam tratamento quantitativo. A pesquisa bibliográfica foi realizada com vistas a buscar, na literatura disponível, informações e conhecimentos anteriores relacionados ao tema: Clima Organizacional, objetivando encontrar respostas sobre suas influências, positivas ou negativas, na consecução dos objetivos organizacionais (Vergara, 2009; Gil, 2010; Pereira et al., 2018).

A pesquisa de campo foi desenvolvida na sede da Secretaria de Educação do Estado da Paraíba (SEE), ambiente laboral desta autora, por meio da qual se pretendeu identificar o grau de satisfação dos seus servidores com os atuais fatores de clima organizacional.

Atualmente, a SEE é composta por 12 Gerências Executivas, oito Subgerências, 12 Gerências Operacionais, além de 14 Gerências Regionais de Educação. Possui uma rede de ensino com 803 escolas e 33 creches, cerca de 22 mil professores atendendo a aproximadamente 400 mil alunos. Funciona com dois órgãos vinculados: a Fundação Centro Integrado de Apoio às Pessoas com Deficiência (FUNAD) e Fundação Casa do Estudante (FUNECAP).

O universo da pesquisa se integrou pelos 197 servidores técnico-administrativos da SEE/Sede, número total atualizado por ocasião da realização desta pesquisa. Para definição da população amostral, estabelecemos alguns critérios de representatividade, intencionais não probabilísticos, sendo eles: ser efetivo; com pelo menos três anos ininterruptos no exercício de suas funções; não estar afastado do trabalho por qualquer motivo, por ocasião da realização da pesquisa; e, ainda, demonstrar livre interesse em participar da mesma. (Vergara, 2009; Gil, 
2010). Ao considerarmos os critérios intencionais não probabilísticos para definição da amostra, verificamos que todos os 197 servidores estavam aptos a participar da pesquisa, no entanto, deste montante, apenas 120 responderam ao questionário, aplicado eletronicamente, entre os dias 08 de setembro a 12 de novembro de 2019.

Os fatos foram observados tal como ocorreram, envolvendo $61 \%$ dos servidores. Os elementos pesquisados para investigação do problema se limitaram às 12 dimensões contempladas pelo Modelo de Burke-Litwin, avaliadas a partir de aplicação de questionário. O diagnóstico do clima organizacional foi realizado a partir da aplicação de questionário estruturado.

Para aferição do clima organizacional, as questões foram relacionadas a uma escala de avaliação integrada por seis alternativas de respostas, que variaram da total discordância ("Discordo Muito") à total concordância (“Concordo Muito”), sendo dada ao respondente a possibilidade de marcar apenas uma das opções.

Na representação da escala, as opções "Concordo Pouco", "Concordo" e "Concordo Muito" são relacionadas à satisfação dos respondentes, do menor para o maior grau. Analogamente, as opções "Discordo Pouco", "Discordo" e "Discordo Muito" representam a insatisfação, ressaltando que a alternativa "Discordo Pouco" indica que o entrevistado não tem uma opinião fortemente definida, representando oportunidade de melhoria.

Uma sétima opção de resposta foi inserida, sendo ela: "Não tenho opinião formada sobre isto/Não sei responder”. Apesar de não se destinar à avaliação do clima organizacional propriamente dito, reduziu o risco de que questões fossem deixadas em branco, no caso do entrevistado não se sentir devidamente seguro em responder, pelo desconhecimento ou insuficiência de informações.

Para a aplicação do questionário, utilizamos a plataforma virtual do Google Drive, referente a Formulários, por se tratar de um recurso largamente utilizado em pesquisas acadêmicas, seja pela sua gratuidade, como pela confiabilidade, acessibilidade e fácil manuseio. Para tanto, as 85 questões tiveram de ser transcritas nesse respectivo meio digital. Os respondentes receberam em seus e-mails, além do convite à participação na pesquisa, o link de acesso à pesquisa. Vale ressaltar que foi dado aos entrevistados um prazo de 60 dias para que pudessem responder o questionário. Os dados, após coletados, foram tabulados e analisados estatisticamente, com o auxílio do programa Excel.

Tendo em vista que dos 197 servidores da sede da SEE, 77 não participaram da pesquisa, julgamos importante identificar prováveis causas, a partir de conversas informais junto aos mesmos, prevalecendo o descrédito quanto à contribuição de pesquisas dessa 
natureza para o seu trabalho, ou mesmo que não tinham tempo para respondê-la, por se tratar de um questionário longo.

\section{Resultados e Discussões}

A análise e a interpretação dos dados foram feitas de modo a se identificar qual o nível de satisfação dos servidores da SEE/Sede em relação aos principais fatores que determinam o clima no ambiente laboral, segundo as dimensões do Modelo de Burke-Litwin.

Das 85 questões que integraram o instrumento de coleta de dados, 82 se basearam em afirmações positivas e três em assertivas negativas (questão 30, 67 e 83). Assim, avaliamos o grau de satisfação a partir das respostas concordantes com as afirmativas positivas e das discordantes com os enunciados negativos.

Conceituamos o grau de satisfação em cada dimensão do clima organizacional avaliada, a partir dos percentuais obtidos nas respostas "Concordo"/“Concordo Muito" para os enunciados positivos e "Discordo"/“Discordo Muito" para os enunciados negativos, estabelecendo uma correlação entre níveis de graus de satisfação e níveis de percentuais obtidos, conforme se vê no Quadro 1.

Quadro 1 - Parâmetros para definição dos graus de satisfação.

\begin{tabular}{|c|c|}
\hline Grau de Satisfação & Percentuais Obtidos nas Respostas \\
\hline Alto & Acima de $80 \%$ \\
\hline Satisfatório & De $71 \%$ a $80 \%$ \\
\hline Mediano & De $50 \%$ a $70 \%$ \\
\hline Baixo & Abaixo de $50 \%$ \\
\hline
\end{tabular}

Fonte: Autores (2019).

Vale ressaltar que a correlação foi estabelecida com base em convenção largamente adotada nos processos de avaliação da aprendizagem realizados nas instituições de ensino e nas avaliações de desempenho organizacional, nos quais a pontuação 7 (sete) costuma ser estabelecida como média, entre o maior e o menor resultado.

Conforme resultados obtidos, 51,3\% foram de respondentes do sexo feminino e $48,7 \%$ do sexo masculino. No nosso entendimento, essa discreta diferença contribuiu para uma representatividade satisfatória de gêneros no processo de produção dos dados.

Em um breve resumo do perfil analisado, verificamos que a adesão dos servidores à pesquisa foi significativa, tendo em vista que $61 \%$ dos servidores em condições de participar 
responderam ao questionário de coleta de dados. Dos entrevistados, delineou-se um perfil positivo aos objetivos deste estudo, uma vez que homens e mulheres participaram em proporção equilibrada, possibilitando uma avaliação que contemplasse as distintas visões de gênero.

O grupo também se revelou de escolaridade elevada, o que contribui para uma análise mais ampla do seu contexto laboral e uma melhor compreensão dos aspectos investigados. A juventude aliada ao pouco tempo de ingresso na administração pública pode ter contribuído para a avaliação positiva que foi feita em relação ao clima organizacional, uma vez que a combinação desses dois fatores geralmente contribui para uma visão otimista quanto à carreira e à ambiência de trabalho (Luz, 2003; Chiavenato, 2008; Vergara, 2014).

A área de maior concentração dos entrevistados foi a Administrativa (76,7\%), ficando as duas áreas juntas, pedagógica e executiva, representadas de maneira menos expressiva, com $23,4 \%$. À época da coleta de informações para divulgação da pesquisa aos participantes, não foi feita a quantificação do percentual de respondentes de cada área da instituição, não sendo possível quantificar o percentual de respondentes que tinha cada área em pesquisa.

A partir da dimensão Ambiente Externo, avaliamos a satisfação dos servidores em relação aos compromissos assumidos pela SEE com os usuários e seu posicionamento em relação às mudanças do setor em que atua, ou seja, Educação. Dois fatores-chave do clima organizacional foram avaliados, com base nas questões de 1 a 6 do questionário de coleta de dados. A estrutura dessa dimensão e os seus resultados podem ser vistos na Tabela 1.

Tabela 1 - Satisfação com o clima organizacional a partir da dimensão ambiente externo.

\begin{tabular}{|c|c|c|c|}
\hline Fator-chave & Questão Avaliada & $\begin{array}{l}\text { \% de Satisfação } \\
\text { Obtido }\end{array}$ & $\begin{array}{c}\text { Grau de } \\
\text { Satisfação } \\
\end{array}$ \\
\hline \multirow{3}{*}{$\begin{array}{l}\text { Enfoque e } \\
\text { Compromisso } \\
\text { com o Usuário }\end{array}$} & $\begin{array}{l}\text { A satisfação dos usuários é uma prioridade dentro da } \\
\text { minha instituição. }\end{array}$ & 74 & Satisfatório \\
\hline & A minha instituição ouve as queixas dos usuários. & 78 & Satisfatório \\
\hline & $\begin{array}{l}\text { A minha instituição utiliza as queixas dos usuários para } \\
\text { melhorar o serviço público prestado. }\end{array}$ & 64 & Baixo \\
\hline \multirow{4}{*}{$\begin{array}{l}\text { Mudanças } \\
\text { Externas }\end{array}$} & $\begin{array}{l}\text { A minha instituição acompanha as mudanças que } \\
\text { ocorrem no serviço público em sua área de atuação. }\end{array}$ & 58 & Baixo \\
\hline & $\begin{array}{l}\text { Tenho conhecimento sobre as mudanças que ocorrem } \\
\text { no setor de atuação da minha instituição. }\end{array}$ & 71 & Satisfatório \\
\hline & $\begin{array}{l}\text { A minha instituição está preparada para as mudanças } \\
\text { que venham a ocorrer no cenário em que está inserida. }\end{array}$ & 48 & Baixo \\
\hline & & Média de Satisfação & $66 \%$ \\
\hline \multicolumn{3}{|c|}{$\begin{array}{l}\text { Grau de Satisfação com o Clima Organizacional a partir da Dimensão Ambiente } \\
\text { Externo }\end{array}$} & Mediano \\
\hline
\end{tabular}

Fonte: Autores (2019). 
De acordo com a Tabela 1, a média obtida nessa dimensão revela que o grau de satisfação dos servidores com a forma como a SEE lida com o seu macro ambiente, abrangendo os compromissos assumidos com usuários e posicionamento em relação às mudanças do seu segmento de atuação, é apenas mediano (66\%).

Diante disso, entendemos que a SEE deve procurar envidar esforços para melhorar sua relação com o ambiente externo, sobretudo com os usuários de seus serviços, por se tratar a educação de um dos bens mais valiosos para qualquer sociedade.

Como a SEE tem por fim maior a promoção de educação de qualidade para todos, precisa ser reconhecida como uma organização onde o conhecimento seja o ativo principal em função de suas pessoas, cultura organizacional, sistemas administrativos, sistemas computacionais, rotinas e procedimentos (Amarante, 2015).

Nessa dimensão do clima organizacional, o resultado mais baixo se deu em função de apenas $48 \%$ dos entrevistados concordarem que a SEE está preparada para as mudanças que venham a ocorrer no segmento de mercado em que está inserida.

De acordo com Robbins (2008, p. 36), "uma das descobertas mais bem documentadas nas pesquisas sobre comportamento organizacional e individual é que as organizações e seus membros resistem à mudança".

Nesta dimensão, avaliamos a clareza e o conhecimento por parte dos servidores quanto aos objetivos e metas da SEE, em consonância com a sua missão, visão e valores. Englobam essa dimensão dois fatores-chave, sendo eles "Clareza de Objetivos e Missão" e "Visão e Valores Difundidos", abrangendo as questões de 7 a 13 do questionário de coleta de dados.

Ressaltamos que na dimensão Missão e Estratégia, tivemos de excluir as respostas dadas à questão de número 12 (“A minha instituição pratica os valores que adota”), tendo em vista que na construção do instrumento de coleta de dados na plataforma virtual, omitimos a opção "concordo muito" da escala de respostas.

A partir da média obtida do conjunto de resultados dessa dimensão, verificamos que a satisfação dos respondentes em relação aos aspectos investigados é apenas mediana, dado o percentual de satisfação ter sido de 59\%.

As fragilidades da SEE, no que concerne à missão e estratégia, residem na percepção dos servidores entrevistados de que o órgão não oferece os recursos necessários para o alcance dos seus objetivos e sua missão não é conhecida e entendida por todos, evidenciando a necessidade de uma ação imediata por parte da SEE, para difusão de sua missão entre seus servidores. 
De acordo com Maximiano (2007, p. 46), "a missão estabelece a utilidade da organização para seus mercados e clientes e para a sociedade. Identificar a missão é entender qual problema a empresa está resolvendo no ambiente".

Dentro desta dimensão Liderança foram contemplados dois fatores-chave: Liderança e Gestão da Mudança. O que se buscou avaliar foi o estilo de liderança adotado pelos gestores da alta administração da SEE, que serve como direcionador e modelo para os servidores. Para a avaliação da satisfação nesses fatores, seis questões foram apresentadas aos respondentes (14 a 19). Por meio dos fatores dessa dimensão, avaliamos a percepção dos servidores acerca do modo como a alta administração conduz o órgão nos aspectos relativos à confiabilidade, credibilidade e comunicação, bem como na gestão da mudança.

Conforme, a média de satisfação obtida nessa dimensão, de apenas $35 \%$, revelou que os servidores da SEE, participantes da pesquisa, estão bastante insatisfeitos com seus gestores estratégicos, sugerindo que o estilo de liderança por eles adotado, não os tem norteado e nem servido de exemplo.

Hersey \& Blanchard (1986) apresentam a liderança como um processo de exercer influência sobre indivíduos ou grupos, agregando esforços para a realização de um objetivo, em uma determinada situação. Assim sendo, a liderança abrange a realização de objetivos com as pessoas e através das pessoas. Por esse motivo, o líder deve estar apto a cuidar tanto de tarefas como de relacionamentos.

A era do conhecimento trouxe grandes desafios para o mundo das organizações. Dentre esses, podemos citar as mudanças evidenciadas na forma de liderar as pessoas no ambiente de trabalho. Se antes as lideranças se pautavam em estilos autoritários, hoje as organizações buscam líderes participativos, flexíveis, intuitivos e com grande espírito de equipe.

Na concepção de Robbins (2008, p. 41), “a principal característica comum a todos os programas de gestão participativa é a tomada de decisão coletiva. Isso quer dizer que os subordinados realmente compartilham um grau significativo de poder de decisão com seus chefes imediatos".

Nesse sentido, cabe aos gestores, para contribuírem com a criação de um clima organizacional saudável e produtivo, dentre outras competências: envolver as pessoas no processo de gestão, fazendo com que se sintam parte dele e, principalmente, serem responsáveis por ele; coordenar as relações entre todos os membros de sua equipe de forma que possibilite uma integração democrática e participativa entre os diversos atores do processo; demonstrar compromisso com a necessidade de mudança; certificar-se de que as 
linhas de comunicação permaneçam bem abertas; construir confiança, o que significa assumir compromissos e cumpri-los; relacionar-se e comunicar-se bem com as pessoas; construir parcerias e compartilhar a liderança; minimizar a vulnerabilidade de sua equipe frente à mudança, e estimular a energia deles para a mudança (Senge, 1990; Luz, 2003; Newstron, 2008; Chiavenato, 2010).

A partir dos fatores-chave "Alinhamento dos Valores Culturais"; "Histórico de Mudanças" e "Prontidão à Mudança" buscamos avaliar o conjunto de regras, valores e princípios explícitos e implícitos que asseguram e orientam o comportamento (cultura) organizacional instalado na SEE. As afirmativas submetidas aos respondentes dentro dessa dimensão são representadas pelas questões de 20 a 25, do instrumento de coleta de dados.

Nessa dimensão, a média geral ficou em torno de $43 \%$, o que caracteriza que os servidores entrevistados têm um baixo grau de satisfação com a cultura organizacional instalada na instituição investigada. Também na dimensão Cultura Organizacional, tivemos que desconsiderar os dados obtidos na questão 24 ("A minha instituição fornece os recursos necessários para a realização das mudanças"), tendo em vista a omissão da alternativa “Concordo Muito", por ocasião da construção da escala de respostas na plataforma virtual.

De acordo com Mintzberg, Ahlstrand \& Lampel (2010), a cultura organizacional é a base da organização e sua força está em legitimar as crenças e os valores compartilhados entre os seus membros e diferenciá-la das demais organizações.

Quanto às pessoas que atuam nas organizações, na opinião de Pires e Macêdo (2006, p. 87), “[...] são agentes que contribuem para esse intercâmbio constante, sendo seus valores componentes para a formação da cultura da organização". Nesse sentido, o clima organizacional é formado pelo compartilhamento das percepções dos membros de uma organização sobre o seu agir, construídas com base na cultura. Essas percepções podem mudar ao longo do tempo, contudo não são características passageiras ou de estado de ânimo da organização, mas padrões de ação e reação, significativas para os membros da organização (Luz, 2003; Ferreira, 2015).

Quanto a fornecer os recursos necessários para a realização das mudanças, $51 \%$ dos entrevistados concordaram que a SEE atua nesse sentido, revelando uma satisfação mediana, ressaltando que nenhum dos servidores participantes da coleta de dados optou pelo nível de concordância mais elevado ("Concordo muito").

Segue a análise da dimensão Estrutura, na qual foi avaliado o grau de satisfação dos sujeitos da pesquisa quanto às funções e dimensionamento das pessoas na organização, para cumprimento dos seus objetivos estratégicos. 
No questionário de coleta de dados, essa dimensão foi avaliada a partir de dois fatoreschave: "Relacionamento Interdepartamental" e "Dimensionamento do Quadro", tendo como base da investigação as questões de 26 a 30.

De acordo a partir da média de satisfação obtida na dimensão Estrutura, de apenas $41 \%$, constatamos que os servidores entrevistados não estão satisfeitos com a maneira como as funções e pessoas estão dispostas na SEE, em áreas e níveis específicos de responsabilidade, tomada de decisão e autoridade.

Consideramos todas as questões que obtiveram percentual de concordância inferior a $50 \%$ como as principais fragilidades da SEE na dimensão Estrutura, ensejando esforços de melhoria, sendo elas: comunicação interdepartamental; trabalho conjunto dos departamentos para alcance dos resultados; carga e pressão advindas do trabalho. Como aspecto positivo, destacou-se que os servidores afirmaram que sabem como o trabalho de suas áreas de atuação está relacionado com o trabalho de outras áreas.

Por se tratar a questão "Muitas vezes fico aborrecido (a) pela quantidade e pressão excessiva do meu trabalho" de uma afirmação negativa, o percentual aferido para avaliação da satisfação foi o de discordância. Nesse sentido, contatamos que apenas $23 \%$ discordaram de que ficam aborrecidos muitas vezes pela quantidade e pressão excessiva do trabalho. A princípio, parece uma informação que contradiz a anterior, no entanto, como a satisfação com o dimensionamento do quadro de pessoal da SEE é apenas mediana, certamente a instituição ainda tem por fazer muitas melhorias no que concerne ao dimensionamento de pessoal e distribuição de funções.

No âmbito dessa dimensão, foram avaliadas as ações adotadas pelos gestores da SEE para execução de sua estratégia, no que concerne à gestão de equipes e dos recursos materiais. Essa dimensão contemplou as questões 31 a 47 do questionário, distribuídas por quatro fatores- chave do clima organizacional, sendo eles: Gestão da liderança; Estilo de Liderança; Gestão de Pessoas; e Comunicação Organizacional.

A questão 44 (“A instituição é tolerante com os servidores que têm baixo desempenho") se trata de uma afirmação negativa ao clima organizacional, por conseguinte o percentual aferido para avaliação da satisfação foram os referentes ao número de servidores que optaram pelas alternativas de discordância.

Conforme a média geral de 53\%, obtida na dimensão Práticas Gerenciais, concluímos que os respondentes estão medianamente satisfeitos com o estilo de liderança e o modelo de gestão de pessoas praticado pelos gestores, para a consecução dos objetivos institucionais. 
No que concerne às práticas gerenciais, ressalta-se, que a maior força da organização investigada está no estilo de liderança dos gestores, sobretudo por elogiarem e reconhecerem seus colaboradores quando realizam um bom trabalho, o que os encoraja a darem o melhor de si para a consecução dos objetivos da SEE.

A baixa satisfação concerniu com os fatores relacionados à gestão de pessoas e à comunicação organizacional, tendo como questões de grande fragilidade do órgão não adequar o seu programa de treinamento às necessidades institucionais, ser tolerante com os servidores que têm baixo desempenho e a inexistência/insuficiência de canais adequados para que seus membros façam sugestões de melhorias.

No atual cenário organizacional, sabe-se, mais do que nunca, que o principal ativo de uma organização é o seu pessoal, e o principal ativo de cada pessoa é a sua competência profissional. A aplicação das energias humanas pode ser infinitamente aumentada quando a organização oferece condições para que os seus colaboradores se desenvolvam de forma programada, desde o seu ingresso.

Nessa dimensão, avaliamos as políticas e mecanismos que facilitam o trabalho, sistemas de informação e controle dentro da SEE, a partir da percepção de seus servidores. No questionário de coleta de dados, a dimensão do clima organizacional relativa a Sistemas se integrou pelas questões 48 a 55, a partir das quais se investigou a satisfação dos respondentes com os seguintes sistemas: Segurança do Trabalho, Qualidade e Informação.

Conforme o grau de satisfação geral dos respondentes com os aspectos dessa dimensão foi considerado baixo, tendo em vista o percentual global de $49 \%$.

Nenhum dos fatores-chave relacionados a Sistemas foi considerado como força da SEE, estando as maiores deficiências reveladas no Sistema de Segurança do Trabalho e no da Qualidade, sendo o mais baixo grau de satisfação dos servidores respondentes ao fato da instituição, provavelmente, não adotar indicadores de desempenho para acompanhar os resultados do trabalho.

É importante explicar que a Secretaria de Estado da Educação possui diversos projetos que são, parcerias nacionais, ou mesmo projetos locais, que possuem seus próprios sistemas informatizados, além dos três sistemas convencionais: administrativo e financeiro (SIAF), pessoal (SAP) e funcional geral (CODATA).

Conforme Mezomo (2001), qualidade é adequação ao uso, incluindo tanto a confiabilidade do produto ou serviço para seus usuários como sua adequação às necessidades deles. "A adequação ao uso tem duas dimensões: a primeira é o perfil do produto ou serviço que atende às necessidades dos clientes (o que afeta a venda) e a segunda é a ausência de 
defeitos (o que afeta os custos). Em outras palavras, conformidade e satisfação do cliente" (Mezomo, 2001, p. 86).

Nesse sentido, a busca pela qualidade não está relacionada ao alcance de uma meta, mas a um processo de melhoramento contínuo, permanente, no qual o atingimento de uma meta desloca a qualidade para níveis superiores.

Por meio da dimensão Requisitos da Tarefa pudemos avaliar aspectos relacionados com o desenho do trabalho, o nível de autonomia, participação e requisitos necessários para o desempenho da tarefa no contexto da SEE.

No questionário de coleta de dados, a dimensão do clima organizacional relativa a Requisitos da Tarefa se integrou pelas questões 56 a 62, a partir das quais se investigou a satisfação dos respondentes com os seguintes sistemas: Procedimentos de Trabalho, Participação dos Servidores e conhecimentos e habilidades.

Nenhum dos fatores-chave relacionados aos Requisitos da Tarefa foi considerado como forças da SEE, estando as maiores deficiências reveladas nos Procedimentos de Trabalho. O mais baixo grau de satisfação dos servidores respondentes se refere ao fato da instituição não explicar adequadamente as mudanças nos procedimentos operacionais, quando as realiza.

Na dimensão "Clima Específico no Setor de Trabalho" foi avaliado o nível de motivação e satisfação geral dos respondentes com o trabalho e a organização. No questionário de coleta de dados, a dimensão do clima específico do setor de trabalho teve como questões: 63 a 72, a partir das quais se investigou a satisfação dos respondentes com os seguintes sistemas: Satisfação com o trabalho, Espírito de Equipe, Soluções de problemas de relacionamento. Conforme o grau de satisfação dos respondentes com os aspectos dessa dimensão foi considerado mediano, tendo em vista o percentual global de $66 \%$.

O fator de maior grau de satisfação foi o espírito de equipe e o entrosamento entre os colaboradores, com um grau satisfação de $81 \%$, o maior nessa dimensão. Isso aponta que mesmo com os problemas nas políticas de valorização do servidor nesta empresa, estes ainda sentem que a sua equipe desempenha um bom trabalho e avaliam que os seus resultados são positivos. Na dimensão Motivação, avaliamos a percepção dos respondentes referente às recompensas, como também tendências comportamentais para agir.

No questionário de coleta de dados, a dimensão do clima organizacional relativa à Motivação se integrou pelas questões 73 a 79, a partir das quais se investigou a satisfação dos respondentes com os seguintes sistemas: Motivação, Reconhecimento e Recompensa. 
Conforme a média geral de 37\% de satisfação, obtida na dimensão Motivação, concluímos que os servidores da SEE, respondentes da pesquisa, estão desmotivados.

A despeito do ambiente de trabalho ser agradável na avaliação dos servidores, com alto índice de satisfação ( $85 \%)$, todos os demais aspectos integrantes dessa dimensão revelam que os respondentes estão insatisfeitos. As questões referentes a salário e benefícios foram as que obtiveram os índices mais baixos de satisfação.

Para Vieira (2011, p.17), “deve-se, no entanto, deixar claro que, considerando as dificuldades encontradas na Administração Pública, principalmente no que diz respeito à gestão de recursos humanos e às condições físicas e estruturais de trabalho, a ideia de motivação torna- se mais complexa".

Na dimensão Comprometimento, avaliamos a percepção dos respondentes referente ao quanto se dedicam e estão dispostos a se comprometerem com os objetivos da organização.

No questionário de coleta de dados, a dimensão do clima organizacional relativa ao Comprometimento se integrou pelas questões 80 a 83, a partir das quais se investigou a satisfação dos respondentes com os aspectos relacionados.

Conforme o grau de satisfação dos respondentes com os aspectos dessa dimensão foi considerado mediano, tendo em vista o percentual global de $61 \%$. O maior grau de satisfação foi constatado na questão de número 83 , uma vez que $77 \%$ dos respondentes discordaram da afirmação "Estou considerando a possibilidade de deixar a instituição".

Na dimensão Pesquisa, avaliamos a percepção dos respondentes referente à reação dos respondentes a pesquisas desta natureza. No questionário de coleta de dados, a dimensão Pesquisa se constituiu das questões 84 e 85 , a partir das quais se investigou a satisfação dos respondentes com os fatores apresentados.

Conforme o grau de satisfação dos respondentes com os aspectos dessa dimensão foi considerado mediano, tendo em vista o percentual global de $63 \%$. Constatou-se que, apesar de 94\% dos respondentes concordarem que esse tipo de pesquisa seja importante, apenas 32\% dos servidores afirmaram que a organização agirá para corrigir os problemas mais sérios identificados na pesquisa.

É importante que essas pesquisas sejam usadas para a melhoria da instituição, do contrário enfraquecem sua utilidade e passam a gerar descrédito nos colaboradores sobre suas reais intenções.

Segundo Barçante (1999), a pesquisa de clima não deve ser realizada novamente até que os resultados possam ser notados pelos clientes internos, entre eles, aumento real dos níveis de satisfação e crescimento do desempenho operacional. 


\section{Considerações Finais}

Esta pesquisa partiu do princípio de que a motivação e a qualidade de vida nas organizações são fortemente influenciadas pela qualidade do clima organizacional prevalecente no ambiente de trabalho. Com os resultados da pesquisa, pode-se avaliar de maneira geral o que se passa no clima da instituição avaliada, a Secretaria de Estado da Educação da Paraíba, e sugerir melhorias de acordo com os temas mais relevantes por dimensão avaliada, na opinião da autora da pesquisa.

O objetivo geral deste trabalho foi diagnosticar a percepção e a satisfação dos servidores da Secretaria de Estado da Educação da Paraíba, em relação ao ambiente de trabalho, através de uma pesquisa de clima organizacional. Para tanto, estabeleceu-se como problema de pesquisa identificar qual o nível de satisfação dos colaboradores da organização pesquisada em relação aos principais fatores que determinam o clima organizacional.

Este objetivo foi alcançado a partir da realização da coleta, análise e interpretação dos dados, que permitiram identificar que os servidores estão medianamente satisfeitos, na medida em que a média geral de satisfação, extraída das 12 dimensões do clima organizacional avaliadas, foi de $53 \%$.

Pode-se concluir que o clima organizacional foi avaliado como medianamente satisfatório pelos servidores respondentes. Nos propusemos a analisar os fatores que influenciam negativamente e/ou positivamente o clima da organização, sugerindo ações que auxiliem a organização na minimização/superação das suas deficiências/fragilidades relativas ao clima organizacional, com base nos resultados obtidos.

\section{Referências}

Amarante, P. (2015). Diagnóstico da gestão do conhecimento em Instituição Federal de Ensino: estratégias de aplicação do método organizacional knowledge assessment. São Paulo/Saarbrucken: Novas Edições Acadêmicas/OmniScriptum GmbH \& Co., 2015.

Barçante, C \& Castro, C. (1999). Ouvindo a voz do cliente interno. 3. ed. Rio de Janeiro.

Bergue, T. (2007). Gestão de pessoas em organizações públicas. 2 eds. rev. e atual. Caxias do Sul, RS: Educs. 
Bispo, CAF. (2006). Um novo modelo de pesquisa de clima organizacional. Production, 16(2), 258-273. https://doi.org/10.1590/S0103-65132006000200007.

Bowditch, J \& Buono, F. (2015). Elementos do Comportamento Organizacional. Ed. Learning.

Burke, W \& Litwin, H. (1992). A musal model of oganizational performance and change. Journal of management, 18(3).

Chiavenato, I. (2008). Administração pública. 2. ed. Rio de Janeiro: Elsevier.

Chiavenato. I. (2010). Iniciação à teoria das organizações. São Paulo: Manole, 2010.

Ferreira, I. (2015). Clima organizacional e qualidade de vida no trabalho. R.Janeiro: LTC.

Gil, C. (2010). Como elaborar projetos de pesquisa. 5.ed. São Paulo: Atlas.

Hersey, P \& Blanchard, H. (1986). Psicologia para administradores: a teoria e as técnicas da liderança situacional. São Paulo: Editora Pedagógica e Universitária.

Luz, R. (2003). Gestão do clima organizacional. Rio de Janeiro: Qualitymark.

Marconi, A \& Lakatos, M. (2006). Técnicas de pesquisa. 6.ed. São Paulo: Atlas.

Maximiano, A. (2007). Introdução à Administração. 7.ed. rev. e ampl. São Paulo: Atlas.

Mezomo, C. (2001). Gestão da qualidade na saúde: princípios básicos. Barueri: Manole.

Marzzoni, D \& Rodrigues, L. (2020). Identificação do perfil dos profissionais contábeis dos escritórios do município de Marabá, Estado do Pará, Brasil. Research, Society and Development, 9 (7), e185973938. doi:http://dx.doi.org/10.33448/rsd-v9i7.3938

Mintzberg, H, Ahlstrand, B \& Lampel, J. (2010). Safári de estratégia: um roteiro pela selva do planejamento estratégico. Porto Alegre: Bookman. 
Pereira, AS, Shitsuka, DM, Parreira, FJ \& Shitsuka, R. (2018). Metodologia da pesquisa científica. [e-book]. Santa Maria. Ed. UAB/NTE/UFSM. Disponível em: https://repositorio.ufsm.br/bitstream/handle/1/15824/Lic_Computacao_MetodologiaPesquisa-Cientifica.pdf? sequence $=1$.

Pires, S \& Macêdo, B. (2010). Cultura organizacional em organizações públicas no Brasil. 2010. Disponível em: <http://dx.doi.org/10.1590/S003476122006000100005>.

Ribeiro, L. (2005). Gestão de pessoas. São Paulo: Saraiva.

Robbins, P. (2008). Comportamento organizacional. 8.ed. São Paulo: Prentice Hall.

Senge, A. (1990). Quinta disciplina: arte e prática da organização que aprende. São Paulo: Best Seller.

Vergara, C. (2015). Gestão de pessoas. 15.ed. São Paulo: Atlas.

Vieira. C. et al. (2011). Motivação na Administração Pública: considerações teóricas sobre a aplicabilidade dos pressupostos das teorias motivacionais na esfera pública. Disponível em: <http://www.admpg.com.br/revista2011/artigos/12.pdf>.

\section{Porcentagem de contribuição de cada autor no manuscrito}

David Nogueira Silva Marzzoni - 50\%

Yanna Patrícia Araújo Pereira - 50\% 